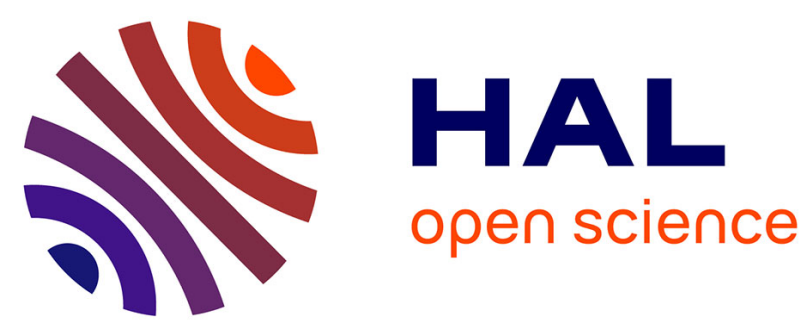

\title{
An avian urban morphotype: how the city environment shapes great tit morphology at different life stages
}

Aude E Caizergues, Anne Charmantier, Marcel M Lambrechts, Samuel Perret, Virginie Demeyrier, Annick Lucas, Arnaud Grégoire

\section{- To cite this version:}

Aude E Caizergues, Anne Charmantier, Marcel M Lambrechts, Samuel Perret, Virginie Demeyrier, et al. An avian urban morphotype: how the city environment shapes great tit morphology at different life stages. Urban Ecosystems, 2021, 10.1007/s11252-020-01077-0 . hal-03120214

\section{HAL Id: hal-03120214 \\ https://hal.science/hal-03120214}

Submitted on 25 Jan 2021

HAL is a multi-disciplinary open access archive for the deposit and dissemination of scientific research documents, whether they are published or not. The documents may come from teaching and research institutions in France or abroad, or from public or private research centers.
L'archive ouverte pluridisciplinaire HAL, est destinée au dépôt et à la diffusion de documents scientifiques de niveau recherche, publiés ou non, émanant des établissements d'enseignement et de recherche français ou étrangers, des laboratoires publics ou privés. 


\section{An avian urban morphotype: how the city environment shapes great tit morphology at different life stages}

Aude E. Caizergues ${ }^{1 *}$, Anne Charmantier ${ }^{1}$, Marcel M. Lambrechts ${ }^{1}$, Samuel Perret $^{1}$, Virginie Demeyrier ${ }^{1}$, Annick Lucas ${ }^{1} \&$ Arnaud Grégoire $^{1}$

Published: 7 january 2021 in Urban Ecosystems

https://doi.org/10.1007/s11252-020-01077-0

- ABSTRACT - Urbanization is a worldwide phenomenon associated with tremendous modifications of natural habitats. Understanding how city dwelling species are affected by those changes is becoming a pressing issue. We presently lack fine scale spatio-temporal studies investigating the impact of urbanization across different life stages and along urbanization gradients. Based on 8 years of monitoring of urban and forest great tits (Parus major), we investigated how city life shapes morphological characteristics at different life stages in the city versus the forest, and within the urban habitat (along naturalness and pedestrian frequency gradients). We found that urban nestlings were significantly smaller than forest ones, but not in lower body condition. Urban breeders showed reduced tarsus, wing and tail lengths compared to forest birds. Within the city, variation in nestling tarsus length and body condition along the naturalness gradient highly depended on the year, with no consistent pattern. For breeders, tarsus length and body condition were positively correlated to the naturalness gradient, although only in 2019 for tarsus, and only in older individuals for body condition. Finally, we found that males had smaller wing lengths in more urbanized parts of the city. These results suggest that urbanization affects morphology early on in development, influencing many morphological attributes. While the mechanisms underlying the urban morphotype remain to be determined, we discuss the potential origins for the documented differences between forest and urban morphotypes, and argue that they most probably result from urban environmental constraints linked to food availability.

- KEYWORDS - avian life stages | morphological variation | plumage allometry | urbanization gradient I urban morphotvpe

${ }^{I}$ CEFE Univ Montpellier, CNRS, Univ Paul Valéry Montpellier 3, EPHE, IRD, Montpellier, France

*Corresponding author : Aude E. Caizergues $\square$ audeemiliecaizergues@gmail.com 


\section{INTRODUCTION}

Urbanization is an increasing worldwide phenomenon driving massive environmental alterations (Marzluff 2001; Gaston et al. 2015). The process of converting land into cities results in new environmental conditions. For instance, compared to non-urbanized habitats, urbanized areas are associated with higher human densities and more impervious surfaces (tarmac roads, concrete ground and buildings) with the remaining green areas often covered with exotic plant species mainly used as decoration (Forman and Godron 1986). Hence, for many organisms, breeding sites, nature and abundance of food resources and human-associated disturbances differ drastically between urban and non-urban habitats (Seress and Liker 2015). Because of these novel environmental features, it is pervasively expected that urban-dwelling organisms should differ from their conspecifics living in less urbanized environments in many of their features, in particular in their development and morphology. Birds are one of the taxa that have most extensively been studied in an urban context, offering the rare opportunity to identify urban-associated drivers of phenotypic divergence (Marzluff 2017).

Availability and abundance of food resources are key factors determining the phenotype of organisms in a given environment. For temperate forest insectivorous passerines, the timing and abundance of resources are important determinants of nestling body condition (Lack 1958; Naef-Daenzer et al. 2001). Reduced vegetation densities and replacement of native plants by exotic ones are responsible for a drastic reduction of insect abundance in urban areas (Jones and Leather 2012; Seress et al. 2018). This lack of food resources can negatively affect birds' morphology, especially nestlings' (Seress et al. 2020). The urban habitat provides numerous novel sources of food (Chamberlain et al. 2009) but the combined effects of lower levels of insect abundance and access to new types of food (e.g. anthropogenic food) might be detrimental for birds during specific stages of their life while being beneficial during others. For instance, human-provided food resources (e.g. seeds in feeders) could be beneficial for adult great tits with a broad diet, but not for their nestlings that rely on insect resources (e.g. Pagani-Núñez et al. 2017). Since many morphological traits are labile throughout life, on a yearly basis (e.g. wing and tail length) or shorter term (e.g. body mass), this might potentially result in different morphotype outcomes in breeders relative to offspring.

The abundance of food resources is not the only constraint on bird development and morphology in cities. Intensified human activities might result in higher ambient temperatures, higher densities of chemical pollutants, and more artificial light and noise, all possibly affecting bird phenotypes directly or indirectly (e.g. Warren et al. 2006, Longcore 2010, Hargitai et al. 2016, Ruiz et al. 2016). For instance, in urban areas with high levels of motorized traffic, heavy metals are common pollutants (Dauwe et al. 2005). Oxidative stress due to these pollutants and the stress induced by human presence have consequences on nutrients assimilation (Dauwe et al. 2005; Müller et al. 2006; Koivula et al. 2011). High levels of oxidative stress could inhibit growth and energy storage, inducing a reduction of body mass and size (Müller et al. 2006; Koivula et al. 2011). Whether oxidative stress has age-dependent effects is still largely unknown. Artificial lights represent another important urban feature influencing morphology since they can induce earlier laying and desynchronization between the peak date of prey availability and the date of maximum nestling prey demand (Kempenaers et al. 2010), resulting in a constrained nestling development. Hence local environmental factors, such as light or chemical pollution, can have behavioral and physiological consequences on bird physiology, foraging or oxidative stress response, all potentially influencing nestling and adult morphology (Müller et al. 2006; Koivula et al. 2011). Importantly, anthropogenic factors might differentially affect birds during different stages of their life, reinforcing the need to study multiple life stages to understand the overall impact of urbanization on city dwelling bird species.

In the context of studying phenotypic responses to a drastically new and constraining environment, such as cities, morphological traits are particularly interesting because i) they are relatively easy to measure, ii) many morphological measures are functionally different hence provide nonredundant information (e.g. regarding health status, dispersal capacities or sexual attractiveness), iii) different morphology-associated traits are often determined at different life stages (i.e. bone size is determined at nestling stage (Gebhardt-Henrich and 
van Noordwijk 1991) while feathers are renewed every year), and (iv) many morphological traits are closely related to survival or reproduction (Lindström 1999). As a result, a large panel of literature already suggests the existence of an urban morphotype in birds. For instance, several studies on great tits, blue tits (Cyanistes caeruleus), house sparrows (Passer domesticus) and common blackbirds (Turdus merula), have found that urban nestlings and adults have lower body condition, associated with lower fledging success, compared to forest birds (e.g. Perrins 1965, Liker et al. 2008, Ibañez-Alamo and Soler 2010, Seress et al. 2012, Bailly et al. 2016). While tarsus length and body condition (or body mass) are classically compared between urban and forest birds, plumage morphometrics, especially wing and tail lengths, are far less studied than sizelinked traits. However, one study on great tits found divergence in nestling wing length (Seress et al 2020), while another study in urban vs. rural mountain chickadees (Poecile gambeli) revealed no such difference in adults (Marini et al. 2017).

One limitation of previous investigations on morphotypes in urban habitats is that they have mainly compared habitats in a binary way, such as forests versus urban parks (e.g. Björklund et al. 2010; Hedblom and Söderström 2012; Markowski et al. 2013; but see Marini et al. 2017; de Satgé et al. 2019). The urban landscape is however very heterogeneous and outside the heavily studied parks it also offers a wide range of more or less urbanized habitats (Amrhein 2013). This important heterogeneity in urban biophysical conditions could translate into contrasted environmental constraints (Alberti 2015), and hence in within-city phenotypic differentiation linked to various human activities.

The present 8-year study aims at improving our understanding of how urban environmental features shape the morphology of wild urban great tits. Our objective was to compare multi-trait morphometrics (tarsus length, body condition and relative wing and tail lengths) at different life stages, between a pair of urban and forest habitats as well as along an urbanization gradient. Our measures include a size and weight measure, but also plumage allometry (wing and tail), in order to explore late development as well as flight aerodynamism (Thomas 1996; Pennycuick 2008). We monitored great tit breeding in nest-boxes in the city of Montpellier and in a nearby oak forest ca. $20 \mathrm{~km}$ from the city. The nest-box distribution in the urban habitat was designed specifically to take into account the wide variety of urban landscapes, as recommended by Amrhein (2013): the monitoring set-up was conducted in areas composed of both parks and residential or commercial streets.

Based on previous findings, we first hypothesized that birds from urban environments would be smaller and display lower body condition compared to forest birds (Caizergues et al. 2018). Comparing morphological divergence at nestling and breeding life stages was instructive to test whether differences in morphology between forest and urban birds were already expressed during growth, and whether urbanization differentially affected individuals during different life stages. Second, we tested whether parent and nestling body condition and morphology also declined across the urban gradient within the city.

\section{MATERIAL AND METHODS}

\section{Study sites}

Between 2012 and 2019, a population of wild urban great tits was monitored annually from March to July in the city of Montpellier, in the south of France $\left(43^{\circ} 36^{\prime} 43^{\prime}\right.$ 'N $\left.3^{\circ} 52^{\prime} 38^{\prime \prime} \mathrm{E}\right)$. Birds bred in nest-boxes installed during the winter 2010-2011. The number of nest-boxes fluctuated between 183 and 222 because of theft or acts of vandalism. Nest-boxes were placed in eight areas of the city (see Figure $\mathrm{S} 2 \mathrm{~A}$ ), in various urban environments from city parks to highly artificialized areas. Within most of the eight urban sites, nest-boxes were distributed in both green areas and along streets (on trees near pavements, roads and street lamps, Figure S2B). A long-term monitoring of great tits and blue tits from an oak forest site ca. $20 \mathrm{~km}$ from the city of Montpellier (La Rouvière forest, $43^{\circ} 64^{\prime} 82^{\prime}$ 'N, $3^{\circ} 69^{\prime} 43^{\prime}$ 'E, Figure $\mathrm{S} 2 \mathrm{C})$ provided similar breeding data during the same period of time (51 to 94 nest-boxes available for great tits across the eight years, Lambrechts et al. 2016).

Different types of nest-boxes were used in the monitoring: wooden squared-based nest boxes of three different sizes (small, medium and large) chosen within the ranges of dimensions accepted by great tits for the purpose of previous study (e.g. Lambrechts et al. 2010, Demeyrier et al. 2016) and more commonly used concrete Schwegler nest-boxes $1 \mathrm{~B}$, with a round base. The different types of nest- 
boxes were distributed randomly across the study area. To limit intraspecific competition, a distance of at least 100 meters separated each nest box from its neighbour.

\section{Breeding monitoring}

From the beginning of the breeding season until the fledgling phase, nest-boxes were visited at least weekly. Because quality and quantity of resources required for nestling growth are expected to significantly change across the breeding season (e.g. Nager and Van Noordwijk 1992), we only focused in this study on nestling data from first clutches, i.e. clutches initiated less than 30 days after the first egg was laid in a given year. Data from second broods or replacement clutches after a failed first breeding attempt were thus not considered. We also excluded broods involved in field experiments, such as brood size manipulation or food-supplementation (Demeyrier et al. 2017). Based on this data filtering, this study included data on 914 (467 females and 447 males) breeding birds trapped between 2013 and 2019 inside nest-boxes while they were feeding 9 to 15 days-old nestlings (hatching is day 0 and age of the brood is the age of the eldest nestling) and on 1576 urban and 1211 forest nestlings. Parents and nestlings were ringed with uniquely numbered metal leg rings provided by the Centre de Recherche Biologique sur les Populations d'Oiseaux (Paris, France). Breeders were sexed based on the presence /absence of a brood patch, and the colour of their wing coverts (Svensson 1992) was used to age them (birds born in the previous breeding season = yearling vs. bird of more than 2 years old $=$ adult). In breeders, we measured the right tarsus length with a calliper $( \pm 0.01 \mathrm{~mm})$, body mass with a Pesola balance $( \pm 0.1 \mathrm{~g})$, and wing length and tail length with a ruler $( \pm 0.5 \mathrm{~mm})$. Wing length was measured from the radius-ulna / carpometacarpus fold (=wirst) to the end of the longest primary remige. For ca 15-day old nestlings, we measured the right tarsus length and body mass using the same field procedures as those applied for breeders. Note that because of fieldwork constraints and of asynchronous hatching, while the majority of nestlings were measured at 15 days, nestling age at measurement varied between 13 and 17 days.

\section{Estimation of urbanization level}

The level of urban disturbance and the potential food resources for great tits was quantified for each nest box, using a radius of 50 meter representing the area where breeders forage more frequently (Perrins 1979).

The measures described below were collected in 2011 (see Demeyrier et al 2016) and repeated in 2018. Since these measures were very stable across time (see Supplementary information 1), we used in this study the 2018 data only, which were collected for all nest-boxes with avian phenotypic measures. Note that while Demeyrier et al (2016) used three measures of vegetation cover (oak cover, tree cover and total vegetation cover), these three measures were highly correlated (Demeyrier et al. 2016: Figure 4) hence only total vegetation cover is used here.

Within 50 meters around each nest box, we measured total vegetation cover (canopy and grass) as proxy for prey availability (Hinsley et al. 2002; Mackenzie et al. 2014). The surface of vegetation cover around each next box was measured on satellite pictures analysed with Q-Gis (version 2.18.16). We also counted motorized traffic and the number of pedestrians to quantify respectively noise and chemical pollution, and human presence (Katti and Warren 2004; Hedblom and Söderström 2012; Aronson et al. 2014). This count was made once for each nest-box during 5 minutes, when ringing nestlings. Finally, light pollution was estimated as the spatial surface of artificial light within 50 meters from each box (Kempenaers et al. 2010) by overlaying a satellite map of each nest-box $50 \mathrm{~m}$ radius area with a satellite map of referenced lampposts and their radius of influence with the Qgis software. A Principal Component Analysis was run on these urban factors and revealed two major axes: PC1 (42.4\% of variance explained) represented the degree of habitat artificiality, named "naturalness gradient" (positive values associated with higher vegetation cover, lower light pollution and lower vehicle traffic), and PC2 (25.4\% of variance explained) represented the "pedestrian frequency" (see Sup Mat Figure S1 for PCA results).

\section{Statistical analyses}

We focused our analyses on four morphological traits: (1) tarsus length, which is used as a proxy of overall body size (because highly correlated with overall bone size, Freeman and Jackson 1990), (2) 
body condition, estimated via the Scaled Mass Index (Peig and Green 2009) which adjusts the mass of individuals as if they all had the same size, and relative (4) wing and (4) tail lengths (measures corrected by tarsus length for each individual see below). To analyze variation in all these traits between habitats and within the urban matrix, we used Linear Mixed-Effect Models (LMM) run with R packages 1me4 and lmerTest (Bates et al. 2015, Kuznetsova et al. 2017; R version 3.5, R Core Team 2018), with a normal error distribution for all nestling and breeder traits. These models allow to use all data collected while accounting for the non-independence of repeated measures on the same individual. Two different sets of models were conducted: first, a global model included the data from the city and the forest to analyze inter-habitat variation and second, an urban model focused on variation within the city. Nestlings and adults were analyzed separately.

We exploited the data from 1576 urban nestlings (363 broods) and 1211 forest nestlings (186 broods) measured between 2012 and 2019. When modeling nestling morphology, explanatory variables were habitat (urban/forest) or naturalness gradient (PC1) and pedestrian frequency (PC2), age (in days), date (as a continuous variable, $1=1$ st of March, standardized per habitat per year), year and the interactions between urban parameters and year (habitat*year or naturalness gradient*year and pedestrian frequency*year). Hour of measure was also added as a continuous fixed effect in the body condition model since weight can vary across daytime (Lange and Leimar 2004). Nest-box identity was included as a random effect in all models since the majority of nest-boxes were occupied more than once across breeding seasons. Mother ring number was also included as a random effect, to account for sibling relatedness as well as maternal environmental/genetic effects. Finally, measurer identity was also included as a random effect to account for differences due to measurement bias.

The analyses on breeder morphology (nurban=640/868; nforest=265/414 for number of individuals/measurement events) were based on data collected between 2013 and 2019. In models on adult morphology, explanatory variables in the full model were: habitat (urban/forest) or naturalness gradient (PC1) and pedestrian frequency (PC2), sex, age (yearling vs. adult), date (as a continuous variable, $1=$ 1st of March, standardized per year), year, and all biologically relevant double interactions (habitat*sex, habitat*age, habitat*year or naturalness gradient*sex, naturalness gradient*age, naturalness gradient*year, pedestrian frequency*sex, pedestrian frequency*age, pedestrian frequency*year, age*sex, and sex*year). Tarsus length was included as a fixed effect in the models explaining wing length and tail length. Thus wing length and tail length hereafter refers to "relative wing length" or "relative tail length". As explained above, daily hour of measure was also added in this model of body mass. Individual ring number was included as a random effect, since numerous breeders were trapped at least twice across breeding seasons (nurban=164 and nforest $=99$ captured at least twice). This individual random effect also encompasses variation in microhabitats since most individuals breed in the same or very close nest-boxes across their reproductive life. Finally, measurer identity was also included as random effect. In all models, random effects were set on the intercept, and were non-nested.

For model selection, we followed a backward stepwise procedure, consisting in removing one non-significant ( $p$-value $>0.05$ ) fixedeffect (simple or in interaction) at each step, starting from the full model (summary of best models are presented in Supplementary Tables S1 to S4). Significance of fixed effects was tested with an analysis of variance (F-test, type III ANOVA), and degrees of freedom were automatically computed with default settings.

When the final model after the above procedure included at least one interaction with habitat, naturalness gradient or pedestrian frequency, we used emmeans (if categorical) or emtrends (if continuous) functions ( $\mathrm{R}$ package emmeans) to obtain estimates per group, and applied post-hoc Tukey HSD tests to assess the significance of a difference between groups (all these results are detailed in Supplementary Tables S5 to S18). In order to check whether models respected linear regression basic assumptions, we ran several tests. First, we tested for multicolinearity between variables via the calculation of the variance inflation factor of models, using vif() function of car package (Fox et al. 2007). Multicolinearity was not an issue since the maximum value of VIF was below 2 for all models. We found no autocorrelation between residuals (Dubin-Watson test, $1.5<\mathrm{d}<1.99$ for all models). Finally, we 
Table 1 | Mean and standard deviation of morphological traits in nestlings and breeder great tits in forest and urban habitats, calculated from the outputs of the best linear mixed models displayed in Table 2 \& 3 using emmeans() R function with default parameters. Tarsus wing and tail lengths are measured in millimetres and body condition in grams. Wing length and tail length are corrected for tarsus length in the linear models. P-values are extracted from the best LMM model habitat effect (see Tables 2, 4, S1 \& S3).

\begin{tabular}{lllccccc}
\hline \multirow{2}{*}{ Life stage } & \multirow{2}{*}{ Trait } & \multicolumn{2}{c}{ Forest } & & \multicolumn{2}{c}{ Urban } & \multirow{2}{*}{ P } \\
\cline { 3 - 4 } \cline { 6 - 8 } & & mean & SE & & mean & SE & \\
\hline \multirow{2}{*}{ Nestling } & Tarsus length & 19.415 & 0.074 & & 18.972 & 0.076 & $<\mathbf{0 . 0 0 1}$ \\
& Body condition & 15.242 & 0.193 & & 15.680 & 0.203 & 0.072 \\
\hline \multirow{3}{*}{ Breeder } & Tarsus length & 19.676 & 0.044 & & 19.409 & 0.036 & $<\mathbf{0 . 0 0 1}$ \\
& Body condition & 16.741 & 0.080 & & 16.845 & 0.074 & 0.141 \\
& Wing length & 74.915 & 0.161 & & 74.179 & 0.154 & $<\mathbf{0 . 0 0 1}$ \\
& Tail length & 63.150 & 0.214 & & 62.406 & 0.193 & $<\mathbf{0 . 0 0 1}$ \\
\hline
\end{tabular}

graphically checked homoscedasticity of residuals, which was respected for all models.

\section{RESULTS}

Forest nestlings overall had longer tarsi than urban nestlings $(\mathrm{P}<0.001$, Table $1 \& 2$ and Figure 1$)$. However, the magnitude of the habitat effect depended on the year as indicated by the significant habitat by year interaction $(\mathrm{P}<0.001$; Table 2 and Figure 1). Forest nestlings had longer tarsi than urban nestlings in 2012 (est. $\pm \mathrm{SE}=0.857 \pm 0.244, \mathrm{P}=0.035$, Table S6), 2017 (est. $\pm \mathrm{SE}=0.589 \pm 0.143, \mathrm{P}=0.004$, Table S6) and 2018 (est. $\pm \mathrm{SE}=0.779 \pm 0.143, \mathrm{P}<0.001$, Table S6), but the difference was not significant for the other years (see Table S6). In addition, the habitat effect on nestling body condition varied across years (significant habitat by year interaction; $\mathrm{P}<0.001$; Table 1 and Figure 1C; see ESM Figure S4 for details) and forest nestlings displayed a significantly lower body condition compared to urban nestlings in 2015 (est. $\pm \mathrm{SE}=-1.505 \pm 0.440, \mathrm{P}=0.046$, Table S6).
Urban breeders had shorter tarsi but not lower body conditions than forest breeders (respectively: $\mathrm{P}<0.001 \& \mathrm{P}=0.141$, Table $1 \& 4$ and Figure 2A \& 2B). Urban breeders also had smaller relative wing lengths compared to forest breeders $(\mathrm{P}<0.001$, Table $1 \& 4$ and Figure $2 \mathrm{C})$, and the magnitude of the urban-forest difference depended on age (significant habitat by age interaction; $\mathrm{P}$ $=0.009$; ESM Table S3). The difference in relative wing length was more pronounced in yearlings (est. $\pm \mathrm{SE}=+0.993 \pm 0.174$ for forest birds, $\mathrm{P}<0.001$; Table S10) than in birds of 2 years or more (est. $\pm \mathrm{SE}=+0.479 \pm 0.160, \quad \mathrm{P}=0.011$; Table $\mathrm{S} 10$ ). Relative tail length was also overall shorter in urban breeders $(\mathrm{P}<0.001$, Table $1 \& 4$ and Figure $2 \mathrm{D})$, but post-hoc tests revealed that the difference was significant only for 2015 (est. $\pm \mathrm{SE}=1.866 \pm 0.416$, $\mathrm{P}<0.001$; Table S12). Finally, yearling breeders had overall smaller morphometrics than older breeders (body condition: est. $\pm \mathrm{SE}=-0.257 \pm 0.049, \mathrm{P}<0.001$;

Table 2 | F-statistics and associated P-values, variance components and sample sizes from final mixed models comparing great tit nestling tarsus length and body condition between forest and urban habitats (type III ANOVA). Detailed outputs and estimates from these models are presented Table S1.

\begin{tabular}{|c|c|c|c|c|c|c|c|c|}
\hline \multirow[b]{2}{*}{ Fixed effects } & \multicolumn{4}{|c|}{ Tarsus length } & \multicolumn{4}{|c|}{ Body condition } \\
\hline & sum sq. & d.f. & $\mathbf{F}$ & $\mathbf{P}$ & sum sq. & d.f. & $\mathbf{F}$ & $\mathbf{P}$ \\
\hline Habitat & 6.654 & 1 & 21.686 & $<0.001$ & 6.353 & 1 & 3.31 & 0.072 \\
\hline Year & 12.087 & 7 & 5.628 & $<0.001$ & 57.481 & 7 & 4.279 & $<0.001$ \\
\hline Habitat x Year & 9.867 & 7 & 4.594 & $<0.001$ & 107.587 & 7 & 8.009 & $<0.001$ \\
\hline Random effects & Var. & \multicolumn{3}{|c|}{ Sample Size } & Var. & \multicolumn{3}{|c|}{ Sample Size } \\
\hline Mother identity & 0.230 & \multicolumn{3}{|c|}{$\mathrm{Nb}$ mothers $=401$} & 1.391 & \multicolumn{3}{|c|}{$\mathrm{Nb}$ mothers $=399$} \\
\hline Nest-box identity & 0.047 & \multicolumn{3}{|c|}{$\mathrm{Nb}$ nest-boxes $=202$} & 0.278 & \multicolumn{3}{|c|}{$\mathrm{Nb}$ nest-boxes $=200$} \\
\hline Observer & 0.031 & \multicolumn{3}{|c|}{$\mathrm{Nb}$ observer $=23$} & 0.256 & \multicolumn{3}{|c|}{$\mathrm{Nb}$ observer $=23$} \\
\hline Residuals & 0.307 & \multicolumn{3}{|c|}{$\mathrm{N}=2792$} & 1.919 & \multicolumn{3}{|c|}{$N=2769$} \\
\hline
\end{tabular}


A
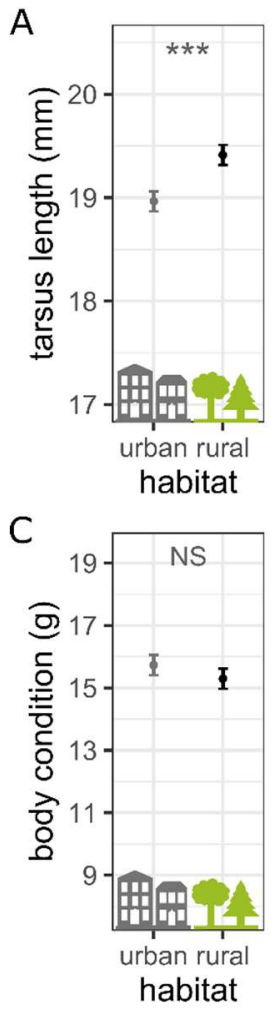
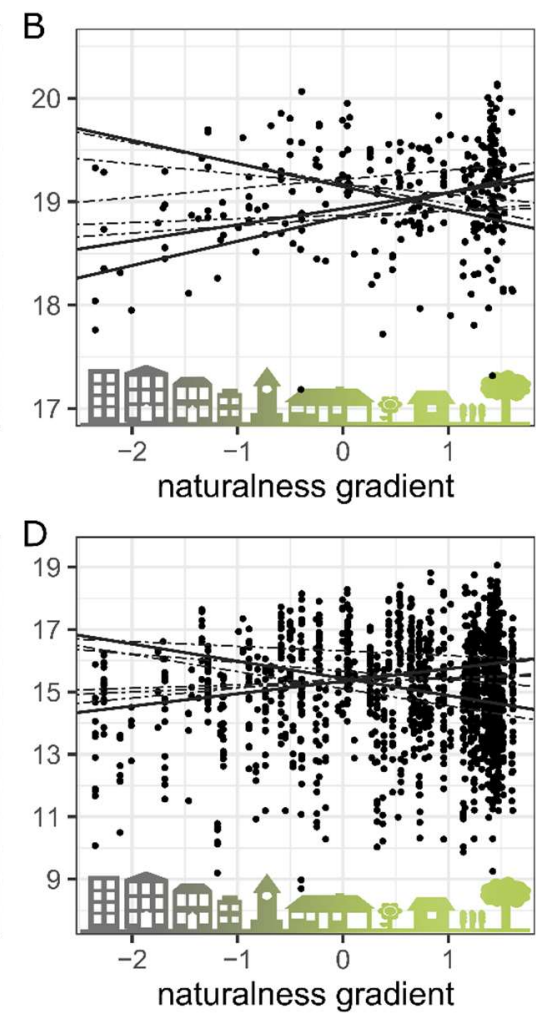

Figure 1 | Morphological divergence in nestling tarsus length and body condition between urban and forest habitats (mean $\pm S E, A$ and $C$ ) and along an urbanization gradient ( $B$ and $D$ ). In $B$ and $C$, points represent individual predicted values output from the best LMM models presented Tables 2 and 3. Intercept and slopes of lines are detailed in supplementary Table S7. , In panels $B$ and $D$, each line represents a year and solid lines represent slopes for which $95 \%$ confidence intervals did not include zero (for B: 2016, 2018 \& 2019; for D: 2015, 2019).

wing length: est. $\pm \mathrm{SE}=-1.076 \pm 0.184, \mathrm{P}<0.001$; tail length: est. $\pm \mathrm{SE}=-1.884 \pm 0.146, \mathrm{P}<0.001$; Table 2 and ESM Table S3), except for tarsus length.

Within the city, the effect of the degree of urbanization on nestling tarsus length varied across years, as indicated by the statistically significant interaction between the naturalness gradient and year $(\mathrm{P}=0.0004$; Table 7 and Figure 1B). Estimates of the regression slopes between naturalness gradient and tarsus length varied between $-0.223( \pm 0.128)$ in 2016 and $+0.235( \pm 0.107)$ in 2019 (see Figure 1B; for detailed estimates see ESM Table S7), and were significantly different between 2016 and 2018 $(\mathrm{P}=0.003$; post-hoc tests presented in Table S8), and 2016 and 2019 ( $\mathrm{P}=0.001$; Table S8). Additionally, there was a significant effect of the naturalness gradient in interaction with year $(\mathrm{P}<0.001$; Table 4; Figure 1D). When looking at detailed slopes per year, only two of them had $95 \%$ credibility intervals non overlapping zero (see Table S7). We also detect a significant effect of pedestrian frequency on nestling tarsus length in 2019 (est. \pm SE $=0.201 \pm 0.097$, Table $\mathrm{S} 7$; $\mathrm{P}=0.043$, Table 3). In 2015, nestlings were in

Table 3 | F-statistics and associated P-values, variance components and sample sizes from final mixed models comparing nestling tarsus length and body condition along gradients of urbanization and pedestrian disturbance (type III ANOVA). Naturalness gradient and pedestrian frequency are synthetic variables obtained by a PCA on measures of vehicles densities, pedestrian count, light pollution and green cover around each nest-box (see supplementary Figure S1). Detailed outputs and estimates from these models are presented Table S2.

\begin{tabular}{|c|c|c|c|c|c|c|c|c|}
\hline \multirow[b]{2}{*}{ Fixed effects } & \multicolumn{4}{|c|}{ Tars us length } & \multicolumn{4}{|c|}{ Body condition } \\
\hline & sum sq. & d.f. & $\mathbf{F}$ & $\mathbf{P}$ & sum sq. & d.f. & $\mathbf{F}$ & $\mathbf{P}$ \\
\hline Naturalness gradient (PC1) & $1.5 \times 10^{-6}$ & 1 & $<1 \times 10^{-22}$ & 0.998 & 0.607 & 1 & 0.275 & 0.601 \\
\hline Pedestrian frequency (PC2) & 0.014 & 1 & 0.041 & 0.840 & n.s. & n.s. & n.s. & n.s. \\
\hline Year & 3.459 & 7 & 1.483 & $<0.001$ & 19.478 & 7 & 1.263 & 0.268 \\
\hline Naturalness gradient $\mathrm{x}$ Year & 9.061 & 7 & 3.885 & $<0.001$ & 44.644 & 7 & 2.893 & 0.006 \\
\hline Pedestrian disturbance $\mathrm{x}$ Year & 4.912 & 7 & 2.106 & 0.043 & n.s. & n.s. & n.s. & n.s. \\
\hline Random effects & Var. & \multicolumn{3}{|c|}{ Sample Size } & Var. & \multicolumn{3}{|c|}{ Sample Size } \\
\hline Mother identity & 0.214 & \multicolumn{3}{|c|}{$\mathrm{Nb}$ mothers $=255$} & 1.385 & \multicolumn{3}{|c|}{$\mathrm{Nb}$ mothers $=255$} \\
\hline Nest-box identity & 0.041 & \multicolumn{3}{|c|}{$\mathrm{Nb}$ nest-boxes $=116$} & 0.226 & \multicolumn{3}{|c|}{$\mathrm{Nb}$ nest-boxes $=116$} \\
\hline Observer & 0.031 & \multicolumn{3}{|c|}{$\mathrm{Nb}$ observer $=14$} & 0.524 & \multicolumn{3}{|c|}{$\mathrm{Nb}$ observer $=14$} \\
\hline Residuals & 0.333 & \multicolumn{3}{|c|}{$N=1556$} & 2.204 & \multicolumn{3}{|c|}{$\mathrm{N}=1554$} \\
\hline
\end{tabular}



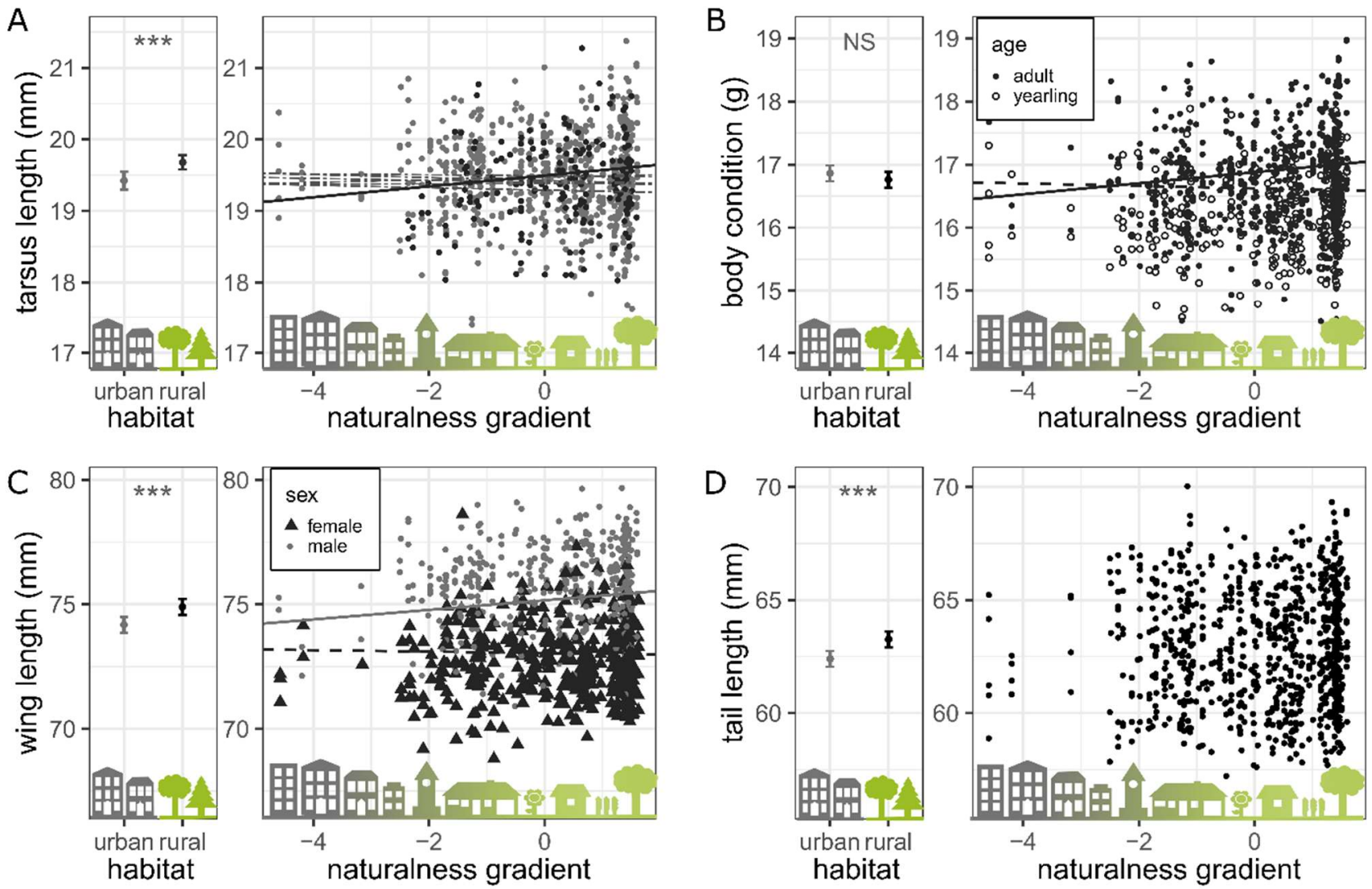

Figure $2 \mid$ Morphological divergence between urban and forest breeders and along an urbanization gradient for (A) tarsus length, (B) body condition, (C) relative wing length and (D) relative tail length. Points represent individual predicted values output from models presented Tables 4 and 5. Detailed intercepts and slopes are presented in Supplementary Table S4 \& S9 to S18. Solid lines represent slopes for which 95\% confidence intervals did not include zero. In A, the black color represents 2019, and grey represent all other years. In B, solid dots and the solid slope represent adult breeders while empty dots and the dashed line represent yearling breeders. In C, grey points and the grey line represent males and black, females.

better body condition in more natural parts of the city (est. $\pm \mathrm{SE}=0.398 \pm 0.264$, Table S7) whereas the reverse was found in 2019 (est. $\pm \mathrm{SE}=-0.551 \pm 0.155$, Table S7), and this difference in slope was confirmed by post-hoc tests between years (ESM Table S2).

Interestingly, significant annual variation was also found for the effect of the naturalness gradient on breeder tarsus length (significant naturalness gradient $\mathrm{x}$ year: $\mathrm{P}=0.035$; Table 5 ). The regression slope between tarsus length and the naturalness gradient was positive for 2019 and it was the only year for which the standard error of the estimate did not include zero (est. $\pm \mathrm{SE}=0.076 \pm 0.029$, $\mathrm{P}<0.001$; Table S13; see Table S14 for post-hoc between years comparisons of annual slopes), meaning that for this year breeders were smaller in the more urbanized parts of the city (Figure 2A).

For breeder body condition, the naturalness gradient by age interaction was statistically significant $(\mathrm{P}=0.023$, Table 5). Body condition of adult urban breeders significantly decreased in more urbanized areas while it was not the case for yearlings for which the slope standard error included zero (est.adult $\pm \mathrm{SE}$ $=0.087 \pm 0.034, \quad$ est.yearling \pm SE $=-0.019 \pm 0.037$; $\mathrm{P}=0.24$; Figure $2 \mathrm{~B}$, Tables $\mathrm{S} 15$ \& $\mathrm{S} 16$ ). Finally, urban breeders were in better physical condition in the highly crowded areas of the city given that there was a statistically significant positive effect of pedestrian frequency on breeder body condition (est. $\pm \mathrm{SE}=+0.076 \pm 0.034 ; \mathrm{P}=0.025$; Table $5 \& \mathrm{~S} 4$ ).

For breeder relative wing length, there was a statistically significant positive interaction between the naturalness gradient and breeder sex $(\mathrm{P}=0.032$, Table 5). In city males, relative wing length increased with increasing habitat naturalness (est. $\pm \mathrm{SE}=0.192 \pm 0.074$ Figure 2C, Table S4, S17 \& $\mathrm{S} 18)$ whereas this effect was close to zero for city females (est. $\pm \mathrm{SE}=-0.029 \pm 0.072$, Figure $2 \mathrm{C}$, Table S4, S17 \& S18). Finally, relative tail length was not correlated with the naturalness gradient. However, breeders had longer tails in more crowded locations (pedestrian frequency effect: est. $\pm \mathrm{SE}=0.19 \pm 0.095$; $\mathrm{P}=0.046$; Table 5 and Table S4). 


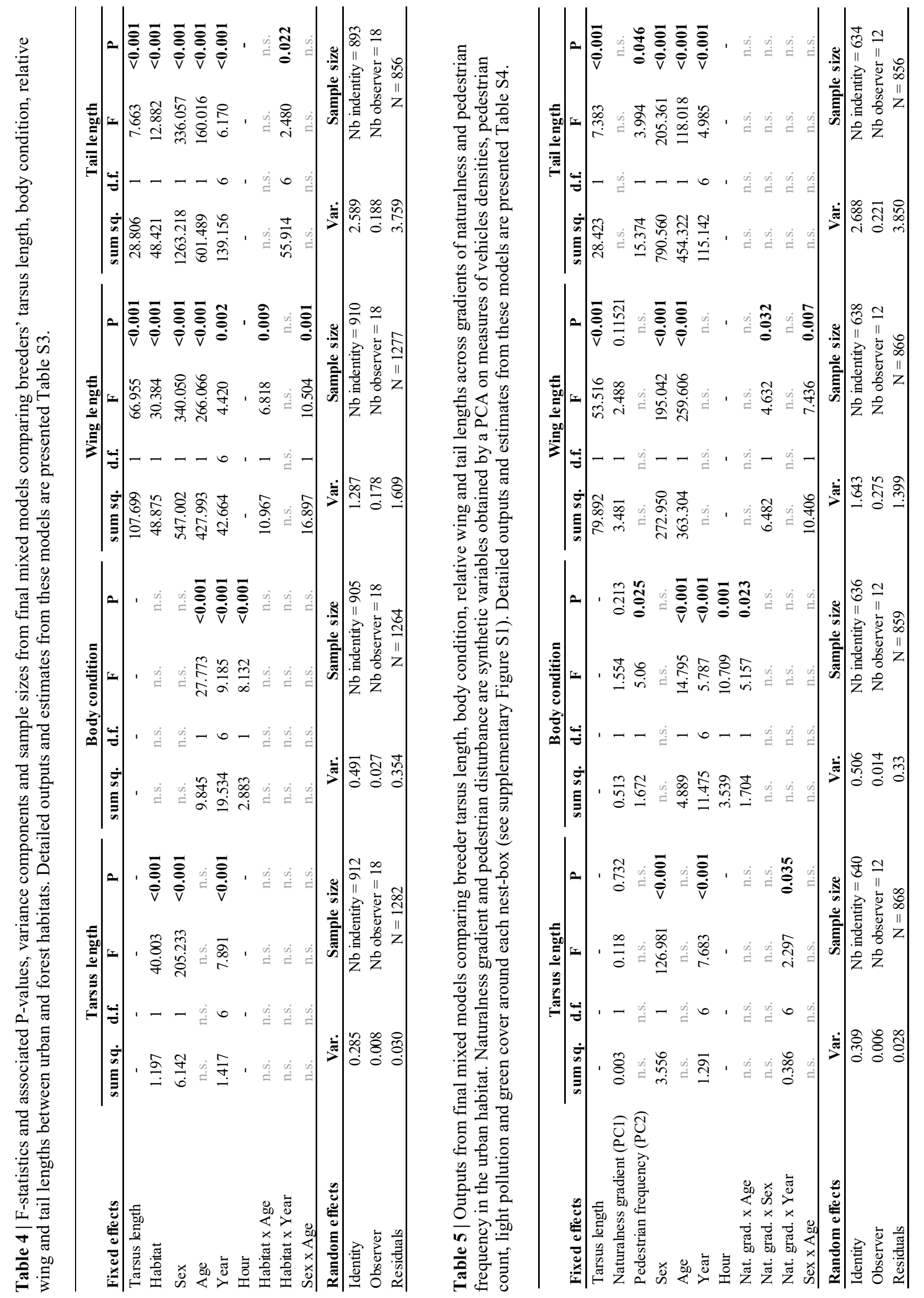




\section{DISCUSSION}

In this study, we aimed to assess the impact of the degree of urbanization on a suite of morphological traits in great tits from southern France (Montpellier), at three life stages: nestling, yearling breeder and older breeder. First, as expected based on previous reports, urban birds were smaller than forest birds. At each life stage, great tits had shorter tarsi in the city than in the forest, which is consistent with findings in previous studies of body size in urban passerines (Liker et al. 2008; Meillère et al. 2015; Biard et al. 2017) although not all (Marini et al. 2017). However, in contrast to a previous study in house sparrows (Meillère et al. 2017), we found no consistent pattern of variation in tarsus length along the naturalness gradient, since the sign of the correlation between tarsus length and the degree of urbanization varied among years in both nestlings and breeders (Figure $1 \mathrm{~B} \& 2 \mathrm{~A})$. Second, we did not detect a significant difference between urban and forest breeders regarding body condition, which contrasts with previous findings of thinner urban individuals (Caizergues et al. 2018, but note the use of a different proxy for body condition) but is in line with results found in other species (e.g. Bókony et al. 2012). However within the city, urban breeders had a lower body condition in the more urbanized areas, as reported by Liker et al. (2008), but only in birds of 2 years or older, not in yearlings. In addition, we found a significant influence of the degree of urbanization on nestling body condition in interaction with year, when comparing urban versus forest nestlings as well as along the naturalness gradient, with estimates changing direction among years. Similar inconsistent results have been reported in the literature (Isaksson and Andersson 2007, Meillère et al. 2017, but see Biard et al. 2017). Surprisingly, however, nestling tarsus length was correlated with pedestrian frequency for the year 2019, and we did not find any report of similar results in the literature.

Finally, urban birds had reduced relative wing and tail lengths compared to forest birds (Figure 2C \& 2D). In addition, male breeders showed reduced relative wing length with increasing urbanization. To our knowledge, such findings on plumage morphometric traits have rarely been reported in the literature (but see for instance Seress et al. 2012 for evidence of shorter wings in urban house sparrow nestlings).

\section{Consequences of living in cities for nestlings}

In birds, bone size, and thus tarsus length, becomes structurally fixed towards the end of the nestling stage (Lindstrom 1999), and poor environmental conditions during development are often associated with smaller structural size (e.g. Seress et al 2012). Thus, reduced size of urban nestlings could result from developmental constraints linked to urban habitat quality (Seress et al. 2018, 2020). For instance, Riddington and Gosler (1995) found lower heritability for tarsus length in great tits living in suburban gardens compared to woodland great tits, suggesting that urbanization might limit nestling growth. However, we also observed that urban nestlings were not consistently in lower body condition than forest nestlings (urban nestlings were thinner than forest nestlings in 2012, 2017 and 2018, but no difference was detected during other years). Perhaps spatial variation in the availability of highquality food might explain why urban nestlings are smaller, but not necessarily in worse physical condition compared to forest nestlings (Isaksson and Andersson 2007). For instance, García-Navas et al. (2013) reported a positive correlation between the proportion of spiders in the diet of nestlings on the one hand and nestling tarsus length on the other hand, which was attributed to the fact that spiders are richer in calcium and taurine than caterpillars. Hence a change in diet constrained by different environmental conditions might result in a change in bone development but not necessary in body condition, which in our case could explain why urban nestlings had shorter tarsi but not always reduced body condition. In addition, growth and bone development might also be affected by chemical pollution and stress. Indeed, heavy metals combined with acidifying agents can reduce calcium assimilation in organisms (Dauwe et al. 2005).

Interestingly, we found that morphology not only expressed significant spatial variation, but also varied substantially between study years. For instance, the difference in body condition between urban and forest nestlings varied among years. In the same line, tarsus length that varied along the naturalness gradient also displayed strong variation across breeding seasons. Hence, inter-annual variation in environmental conditions is probably important in our system and should be further explored via the quantification of both food quantity 
and quality across years and study areas. For example, a recent review highlighted that resources and habitat structure are more stable between years in urban than in natural habitats (Leveau 2018). Finally, nestling tarsus within the city was positively correlated with the pedestrian frequency gradient. This could either be associated with pedestrianassociated resources (wastes) or result from an alteration of parental care patterns and time constraints in the presence of human pedestrians. For instance, humans might scare away bird predators and birds habituated to the presence of humans might therefore be given more time to look for insect prey required to feed the nestlings (Møller 2012).

\section{Consequences of living in cities for breeders}

As discussed above, the shorter tarsi of urban birds were already observed at the nestling stage, suggesting that constraints during nestling development affect breeders' morphology. Interestingly, the difference in tarsus length between forest and urban birds was larger for nestlings than for breeders (mean differences of $0.443 \mathrm{~mm}$ for nestlings versus $0.265 \mathrm{~mm}$ for adults, Table 1 ). While great tit tarsi have usually reached their final size when measured on 14-15 days old nestlings (Orell 1983), data on nestling growth in urban areas might reveal that the time needed to reach an asymptotic size is longer in the city. Alternatively, a larger difference in size between urban and forest nestlings compared to adults could also result from survival selection favouring taller nestlings in the city. Future demographic field studies will allow to test whether smaller city fledglings have lower survival.

In addition, we did not detect a difference in body condition between urban and forest breeders which contrast with other studies in this and other populations of great tit (Caizergues et al. 2018). This result suggests that urban great tits could compensate for fewer resources by being smaller and hence maintain a similar body condition compared to forest great tits. However, within the city, body condition of adult birds increased significantly in more natural areas which is not the case for yearlings that have a lower and constant body condition all along the gradient (Figure 2B). This result indicates that food availability might be reduced in more urbanized parts of the city. For instance, Hinsley et al. (2008) reported that in patchy urban habitats the daily energy expenditure of female great tits increased by $64 \%$ per nestling. This indicates that increased parental foraging effort during the nestling stage can lower body condition of breeders facing a depleted urban habitat. One hypothesis for the difference observed between adults and yearlings is that more experienced adult birds are able to better exploit their environment and maintain high body condition but only in the greener areas of the city. While one-yearold birds are too novice to optimally explore their habitat or secure high-quality territories and thus present lower body condition in all parts of the city. Future studies will be required to examine whether the urban morphotype is adaptive. For instance, body condition might be associated with resource predictability (Cuthill et al. 2000), with e.g. high food predictability associated with a significant reduction in body reserves (Shochat 2004). Knowledge on the composition of the urban great tit diet and its spatiotemporal variation would once again be instrumental in this context. We therefore currently do not reject the hypothesis that a reduction in body condition can be plastically or genetically adaptive in more urbanized habitats. While previous selection analyses did not reveal any reproductive advantage for breeders with lower body condition in the city (Caizergues et al. 2018), survival advantages could occur and need to be evaluated.

Similarly, the urban great tit morphotype was characterized by shorter relative wing and tail lengths compared to forest birds, as well as shorter relative wing length along the naturalness gradient (in males only). To our knowledge, very few studies have investigated the link between urbanization and plumage length in passerines. Marini et al. (2017), found no relation between level of urbanization and wing and tail lenghts in mountain chickadee. On the contrary, a recent study of Seress et al. (2020) found shorter wings in great tit nestlings. Differences in wing and tail lengths could result from urban constraints or be adaptive. In the first scenario, shorter feathers in city birds could be explained by increased diet-associated constraints in the city since feather growth is costly, especially in a context of protein deprivation (Saino et al. 2013). Previous investigations used feather quality as a proxy to assess the nutritional and energetic constraints acting during molt or breeding (Nilsson and Svenssonn 1996). In addition, Meillère et al. (2017) reported a decrease in feather quality (i.e. density) along the naturalness gradient in juvenile birds. In an 
alternative scenario, rather than resulting from urban constraints, smaller wings and tails might be adaptive in cities. Previous selection analyses relating reproductive success to wing and tail lengths did not reveal any breeding selection on these traits in the city nor in the forest (see Table 3 in Caizergues et al., 2018); however, it is likely that natural selection could act via survival rather than reproductive success. For instance, plumage traits are closely linked to flight aerodynamics, and thereby can be important features determining predator or obstacle avoidance (Rayner 1988). In particular, shorter wings confer higher maneuverability (Rayner 1988, Thomas 1996), which could be crucial to avoid collision with moving vehicles or to escape from cats. For instance, in a population of cliff swallows (Petrochelidon pyrrhonota) nesting near a highway, individuals collected after collision deaths had longer wings than the rest of the study population which suggested survival selection favoring shorter-winged swallows (Brown and Bomberger Brown 2013). In line with these findings, we found that male great tits had shorter wings in areas with denser traffic (Table 5). Survival studies using capture-recapture histories will be required to further explore the association between wing length and traffic density.

\section{Going further}

This study examined in a multi-dimensional way the urban morphotype and we mainly discuss the urban constraints that could result in a plastic morphotype. However, our study is of correlative nature, and future studies will need to (1) identify environmental drivers explaining the urban morphotype, (2) test for a plastic versus genetic origin in the forest / city differences described here, and (3) test for the adaptive nature of these differences (Perrier et al. 2020). Experimental tests manipulating different environmental condition (pollution, access to resources, disturbance) and comparing forest and city birds raised in similar conditions (cross-fostering and/ or common garden) will be most efficient to tackle these questions.

Also, our comparative field study focused on a single pair of study populations. Because different cities share many environmental features, they offer multiple opportunities to replicate our study approaches on the same or on other species. Hence, we hope that in the near future, such multi-stage comparison of forest and urban morphotypes will be conducted across multiple cities.

\section{DECLARATIONS}

\section{FUNDING}

This project was funded by the European Research Council (starting grant no. ERC-2013-StG-337365SHE to AC) and a long-term support from OSUOREME.

\section{CONFLICTS OF INTEREST/ COMPETING INTERESTS}

We declare we have no conflicts of interest and no competing interests.

\section{ACKNOWLEDGEMENT}

We would like to warmly thank everyone who participated in the fieldwork since 2011, especially the PLT platform of the CEFE, Pablo Giovannini, Baptiste Pépin, Arnaud Borne, the GNUM, the city Council of Montpellier and the Zoo de Lunaret. We thank the SIE platform of the CEFE and Christophe de Franceschi for managing the database. Finally, we would like to thank reviewers for their useful comments.

\section{ETHICS APPROVAL}

Captures were performed under personal ringing permits delivered by the CRBPO (Centre de Recherches par le Baguage des Populations d'Oiseaux, e.g. ringing permit for Anne Charmantier and Arnaud Grégoire were number 1907 \& 1904) for the Research Ringing Programme number 369. All experimental protocols were approved by the ethics committee for animal experimentation of Languedoc Roussillon (CEEA-LR, most recent approval on $05 / 06 / 2018$ ) as well as by Regional Institutions (bylaw issued by the Prefecture $n^{\circ} 2012167-003$ ).

\section{AUTHORS CONTRIBUTIONS}

AEC participated in data collection, carried out the statistical analyses, and wrote the manuscript. ML, $\mathrm{AG}$ and $\mathrm{AC}$ conceived and funded the study, collected the data and contributed to the writing of the manuscript. SP, VD and AL participated in the data collection. All the authors gave final approval for publication. 
All data and custom codes used in this study are available on Hal platform: hal.archives-ouvertes.fr/

\section{BIBLIOGRAPHY}

Alberti M (2015) Eco-evolutionary dynamics in an urbanizing planet. Trends Ecol Evol 30:114-126. https://doi.org/10.1016/j.tree.2014.11.007

Amrhein V (2013) Wild bird feeding (probably) affects avian urban ecology. In: Avian Urban Ecology, Oxford Uni. Oxford, UK, pp 29-37

Aronson MFJ, La Sorte FA, Nilon CH, et al (2014) A global analysis of the impacts of urbanization on bird and plant diversity reveals key anthropogenic drivers. Proc $R$ Soc B Biol Sci 281:20133330-20133330. https://doi.org/10.1098/rspb.2013.3330

Bailly J, Scheifler R, Berthe S, et al (2016) From eggs to fledging: negative impact of urban habitat on reproduction in two tit species. J Ornithol 157:377392. https://doi.org/10.1007/s10336-015-1293-3

Bates D, Mächler M, Bolker B, Walker S (2015) Fitting Linear Mixed-Effects Models Using lme4. J Stat Softw 67:1-48. https://doi.org/10.18637/jss.v067.i01

Biard C, Brischoux F, Meillère A, et al (2017) Growing in Cities: An Urban Penalty for Wild Birds? A Study of Phenotypic Differences between Urban and Rural Great Tit Chicks (Parus major). Front Ecol Evol 5:. https://doi.org/10.3389/fevo.2017.00079

Björklund M, Ruiz I, Senar JC (2010) Genetic differentiation in the urban habitat: The great tits (Parus major) of the parks of Barcelona city. Biol $J$ Linn Soc 99:9-19. https://doi.org/10.1111/j.10958312.2009.01335.x

Bókony V, Seress G, Nagy S, et al (2012) Multiple indices of body condition reveal no negative effect of urbanization in adult house sparrows. Landsc Urban Plan $104: 75-84$ https://doi.org/10.1016/j.landurbplan.2011.10.006

Brown CR, Bomberger Brown M (2013) Where has all the road kill gone? Curr Biol 23:R233-R234. https://doi.org/10.1016/J.CUB.2013.02.023

Caizergues AE, Grégoire A, Charmantier A (2018) Urban versus forest ecotypes are not explained by divergent reproductive selection. Proc $R$ Soc $B$ Biol Sci 285:20180261.

https://doi.org/10.1098/rspb.2018.0261

Chamberlain D, Hatchwell B, Gaston KJ (2009) Avian productivity in urban landscapes: A review and metaanalysis Avian productivity in urban landscapes : a review and meta-analysis. Ibis (Lond 1859) 1-18. https://doi.org/10.1111/j.1474-919X.2008.00899.x

Cuthill IC, Maddocks SA, Weall C V., Jones EKM (2000) Body mass regulation in response to changes in feeding predictability and overnight energy expenditure. Behav Ecol

11:189-195. https://doi.org/10.1093/beheco/11.2.189

Dauwe T, Janssens E, Pinxten R, Eens M (2005) The reproductive success and quality of blue tits (Parus caeruleus) in a heavy metal pollution gradient. Environ Pollut 136:243-251. https://doi.org/10.1016/J.ENVPOL.2005.01.009

de Satgé J, Strubbe D, Elst J, et al (2019) Urbanisation lowers great tit Parus major breeding success at multiple spatial scales. J Avian Biol 50:jav.02108. https://doi.org/10.1111/jav.02108

Demeyrier V, Charmantier A, Lambrechts MM, Grégoire A (2017) Disentangling drivers of reproductive performance in urban great tits: a food supplementation experiment. $J$ Exp Biol 220:4195-4203. https://doi.org/10.1242/jeb.161067

Demeyrier V, Lambrechts MM, Perret P, Grégoire A (2016) Experimental demonstration of an ecological trap for a wild bird in a human-transformed environment. Anim Behav 118:181-190. https://doi.org/10.1016/J.ANBEHAV.2016.06.007

Forman RTT, Godron M (1986) Landscape Ecology. John Wiley and Sons, New York

Fox J, Friendly GG, Graves S, et al (2007) The car package. R Foundation for Statistical Computing, Vienna, Austria

Freeman S, Jackson WM (1990) Univariate Metrics Are Not Adequate to Measure Avian Body Size. Auk 107:69-74. https://doi.org/10.1093/AUK/107.1.69

García-Navas V, Ferrer ES, Sanz JJ (2013) Prey choice, provisioning behaviour, and effects of early nutrition on nestling phenotype of titmice. Écoscience 20:9-18. https://doi.org/10.2980/20-1-3545

Gaston KJ, Visser ME, Hölker F (2015) The biological impacts of artificial light at night: the research challenge. Philos Trans $R$ Soc B Biol Sci 370:20140133. https://doi.org/10.1098/rstb.2014.0133

Gebhardt-Henrich SG, van Noordwijk AJ (1991) Nestling growth in the Great Tit I. Heritability estimates under different environmental conditions. J Evol Biol 4:341362 . https://doi.org/10.1046/j.14209101.1991.4030341.x

Hargitai R, Nagy G, Nyiri Z, et al (2016) Effects of breeding habitat (woodland versus urban) and metal pollution on the egg characteristics of great tits (Parus major). Sci Total Environ 544:31-38. https://doi.org/10.1016/J.SCITOTENV.2015.11.116

Hedblom M, Söderström B (2012) Effects of urban matrix on reproductive performance of Great Tit (Parus major) in urban woodlands. Urban Ecosyst 15:167180. https://doi.org/10.1007/s1 1252-011-0204-5

Hinsley SA, Hill RA, Bellamy PE, et al (2008) Effects of structural and functional habitat gaps on breeding woodland birds: Working harder for less. Landsc Ecol 23:615-626. https://doi.org/10.1007/s10980-0089225-8

Hinsley SA, Hill RA, Gaveau DLA, Bellamy PE (2002) Quantifying woodland structure and habitat quality for birds using airborne laser scanning. Funct Ecol 16:851-857. https://doi.org/10.1046/j.13652435.2002.00697.x

Ibañez-Alamo JD, Soler M (2010) Does urbanization affect selective pressures and life-history strategies in the common blackbird (Turdus merula L.)? Biol J Linn Soc 101:759-766. https://doi.org/10.1111/j.10958312.2010.01543.x

Isaksson C, Andersson S (2007) Carotenoid diet and nestling provisioning in urban and rural great tits Parus major. $J$ Avian Biol 38:564-572. https://doi.org/10.1111/j.2007.0908-8857.04030.x 
Jones EL, Leather SR (2012) Invertebrates in urban areas: A review. Eur J Entomol 109:463-478. https://doi.org/10.14411/eje.2012.060

Katti M, Warren PS (2004) Tits, noise and urban bioacoustics. Trends Ecol Evol 19:109-110. https://doi.org/10.1016/J.TREE.2003.12.006

Kempenaers B, Borgström P, Loës P, et al (2010) Artificial Night Lighting Affects Dawn Song, Extra-Pair Siring Success, and Lay Date in Songbirds. Curr Biol 20:1735-1739. https://doi.org/10.1016/J.CUB.2010.08.028

Koivula MJ, Kanerva M, Salminen J-P, et al (2011) Metal pollution indirectly increases oxidative stress in great tit (Parus major) nestlings. Environ Res 111:362-370. https://doi.org/10.1016/J.ENVRES.2011.01.005

Kuznetsova A, Brockhoff PB, Christensen RHB (2017) lmerTest Package: Tests in Linear Mixed Effects Models. J Stat Softw 82:. https://doi.org/10.18637/jss.v082.i13

Lack D (1958) A quantitative breeding study of British tits. Ardea 91-124

Lambrechts MM, Adriaensen F, Ardia DR, et al (2010) The Design of Artificial Nestboxes for the Study of Secondary Hole-Nesting Birds: A Review of Methodological Inconsistencies and Potential Biases. Acta Ornithol 45:1-26. https://doi.org/10.3161/000164510X516047

Lambrechts MM, Blondel J, Bernard C, et al (2016) Exploring Biotic and Abiotic Determinants of Nest Size in Mediterranean Great Tits (Parus major) and Blue Tits (Cyanistes caeruleus). Ethology 122:492501. https://doi.org/10.1111/eth.12494

Lange H, Leimar O (2004) Social stability and daily body mass gain in great tits. Behav Ecol 15:549-554. https://doi.org/10.1093/beheco/arh044

Leveau LM (2018) Urbanization, environmental stabilization and temporal persistence of bird species: A view from Latin America. PeerJ 2018:e6056. https://doi.org/10.7717/peerj.6056

Liker A, Papp Z, Bókony V, Lendvai ÁZ (2008) Lean birds in the city: Body size and condition of house sparrows along the urbanization gradient. J Anim Ecol 77:789-795. 2656.2008.01402.x

Lindström (1999) Early development and fitness in birds and mammals. Trends Ecol Evol 14:343-348. https://doi.org/10.1016/s0169-5347(99)01639-0

Longcore T (2010) Sensory Ecology: Night Lights Alter Reproductive Behavior of Blue Tits. Curr Biol 20:R893-R895.

https://doi.org/10.1016/J.CUB.2010.09.011

Mackenzie JA, Hinsley SA, Harrison NM (2014) Parid foraging choices in urban habitat and their consequences for fitness. Ibis (Lond 1859) 156:591605. https://doi.org/10.1111/ibi.12166

Marini KLD, Otter KA, LaZerte SE, Reudink MW (2017) Urban environments are associated with earlier clutches and faster nestling feather growth compared to natural habitats. Urban Ecosyst 20:1291-1300. https://doi.org/10.1007/s11252-017-0681-2

Markowski M, Kaliński A, Skwarska J, et al (2013) Avian Feathers as Bioindicators of the Exposure to Heavy Metal Contamination of Food. Bull Environ Contam
Toxicol 91:302-305. https://doi.org/10.1007/s00128013-1065-9

Marzluff JM (2001) Worldwide urbanization and its effects on birds. In: Marzluff JM, Bowman R, Donnelly R (eds) Avian Ecology and Conservation in an Urbanizing World. Springer US, Boston, pp 19-47

Marzluff JM (2017) A decadal review of urban ornithology and a prospectus for the future. Ibis (Lond 1859) 159:1-13. https://doi.org/10.1111/ibi.12430

Meillère A, Brischoux F, Henry PY, et al (2017) Growing in a city: Consequences on body size and plumage quality in an urban dweller, the house sparrow (Passer domesticus). Landsc Urban Plan 160:127-138. https://doi.org/10.1016/j.landurbplan.2016.12.014

Meillère A, Brischoux F, Parenteau C, Angelier F (2015) Influence of urbanization on body size, condition, and physiology in an urban exploiter: A multi-component approach. PLoS One 10:1-19. https://doi.org/10.1371/journal.pone.0135685

Møller AP (2012) Urban areas as refuges from predators and flight distance of prey. Behav Ecol 23:1030-1035. https://doi.org/10.1093/beheco/ars067

Müller C, Jenni-Eiermann S, Blondel J, et al (2006) Effect of human presence and handling on circulating corticosterone levels in breeding blue tits (Parus caeruleus). Gen Comp Endocrinol 148:163-171. https://doi.org/10.1016/J.YGCEN.2006.02.012

Naef-Daenzer B, Widmer F, Nuber M (2001) Differential post-fledging survival of great and coal tits in relation to their condition and fledging date. J Anim Ecol 70:730-738. https://doi.org/10.1046/j.00218790.2001.00533.x

Nager RG, Van Noordwijk AJ (1992) Energetic limitation in the egg-laying period of great tits. Proc R Soc B Biol Sci https://doi.org/10.1098/rspb.1992.0112 249:259-263.

Nilsson JA, Svenssonn E (1996) The cost of reproduction: A new link between current reproductive effort and future reproductive success. Proc $R$ Soc B Biol Sci 263:711-714. https://doi.org/10.1098/rspb.1996.0106

Orell M (1983) Nestling growth in the great tit Parus major an the willow tit P. montanus. Ornis Fenn 60:65-82

Pagani-Núñez E, Renom M, Mateos-Gonzalez F, et al (2017) The diet of great tit nestlings: Comparing observation records and stable isotope analyses. Basic Appl Ecol 18:57-66. https://doi.org/https://doi.org/10.1016/j.baae.2016.11. 004

Peig J, Green AJ (2009) New perspectives for estimating body condition from mass/length data: the scaled mass index as an alternative method. Oikos 118:1883-1891. https://doi.org/https://doi.org/10.1111/j.16000706.2009.17643.x

Pennycuick CJ (2008) Modelling the flying bird. Theor Ecol Ser 1-480. https://doi.org/10.1007/s13398-0140173-7.2

Perrier C, Caizergues AE, Charmantier A (2020) Adaptation Genomics in Urban Environments. In: Szulkin M, Munshi-South J, Charmantier A (eds) Urban Evolutionary Biology. Oxford University Press, pp 72-88 
Perrins CM (1965) Population Fluctuations and ClutchSize in the Great Tit, Parus major L. J Anim Ecol 34:601. https://doi.org/10.2307/2453

Perrins CM (1979) British tits. Collins, London, UK

R Core Team (2018) R: A language and environment for statistical computing. R Foundation for Statistical Computing, Vienna, Austria http://www.Rproject.org/

Rayner JM V. (1988) Form and Function in Avian Flight. In: Current Ornithology. Springer US, Boston, MA, pp $1-66$

Riddington R, Gosler AG (1995) Differences in reproductive success and parental qualities between habitats in the Great Tit Parus major. Ibis 137:371$378 . \quad$ https://doi.org/10.1111/j.1474919X.1995.tb08035.x

Ruiz S, Espín S, Rainio M, et al (2016) Effects of dietary lead exposure on vitamin levels in great tit nestlings An experimental manipulation. Environ Pollut 213:688-697. https://doi.org/10.1016/J.ENVPOL.2016.03.042

Saino N, Romano M, Caprioli M, et al (2013) Molt, feather growth rate and body condition of male and female Barn Swallows. J Ornithol 154:537-547. https://doi.org/10.1007/s10336-012-0924-1

Seress G, Bókony V, Pipoly I, et al (2012) Urbanization, nestling growth and reproductive success in a moderately declining house sparrow population. $J$ Avian Biol 43:403-414. https://doi.org/10.1111/j.1600-048X.2012.05527.x

Seress G, Hammer T, Bókony V, et al (2018) Impact of urbanization on abundance and phenology of caterpillars and consequences for breeding in an insectivorous bird. Ecol Appl 28:1143-1156. https://doi.org/10.1002/eap.1730

Seress G, Liker A (2015) Habitat urbanization and its effects on birds. Acta Zool Acad Sci Hungaricae 61:373-408.

https://doi.org/10.17109/AZH.61.4.373.2015

Seress G, Sándor K, Evans KL, Liker A (2020) Food availability limits avian reproduction in the city: An experimental study on great tits Parus major. J Anim Ecol 1365-2656.13211. https://doi.org/10.1111/13652656.13211

Shochat E (2004) Credit or debit? Resource input changes population dynamics of city-slicker birds. Oikos 106:622-626

Svensson L (1992) Identification guide to European passerines. Lars Svensson, Stockholm

Thomas ALR (1996) The Flight of Birds that have Wings and a Tail: Variable Geometry Expands the Envelope of Flight Performance. J Theor Biol 183:237-245. https://doi.org/10.1006/JTBI.1996.0217

Warren PS, Katti M, Ermann M, Brazel A (2006) Urban bioacoustics: it's not just noise. Anim Behav 71:491502. https://doi.org/10.1016/J.ANBEHAV.2005.07 
